\title{
Mobility in osteogenesis imperfecta: a multicenter North American study
}

\author{
Karen M. Kruger, $\mathrm{PhD}^{1,2}$, Angela Caudill, PT, MPT'2, Mercedes Rodriguez Celin, MD², \\ Sandesh C. S. Nagamani, MD ${ }^{3,4}$, Jay R. Shapiro, MD ${ }^{5,6}$, Robert D. Steiner, $\mathrm{MD}^{7,8}$, \\ Michael B. Bober, MD ${ }^{9}$, Tracy Hart, BS ${ }^{10}$, David Cuthbertson, $\mathrm{MS}^{11}$, Jeff Krischer, PhD ${ }^{11}$, \\ Peter H. Byers, MD ${ }^{12}$, Michaela Durigova, PhD ${ }^{13}$, Francis H. Glorieux, MD, PhD ${ }^{13}$, Frank Rauch, $\mathrm{MD}^{13}$, \\ V. Reid Sutton, $\mathrm{MD}^{3,4}$, Brendan Lee, MD, PhD ${ }^{3,4}$, Eric T. Rush, MD ${ }^{14}$, Peter A. Smith, $\mathrm{MD}^{2}$ and \\ Gerald F. Harris, PhD ${ }^{1,2}$
}

Purpose: Osteogenesis imperfecta (OI) is a genetic connective tissue disorder that causes bone fragility. Phenotypic severity influences ability to walk, however, little is known about ambulatory characteristics of individuals with OI, especially in more severe forms. The purpose of this work was to characterize mobility in OI using standard clinical assessment tools and determine if patient characteristics could be used to predict mobility outcomes.

Methods: We collected mobility data at five clinical sites to analyze the largest cohort of individuals with OI $(n=491)$ to date. Linear mixed models were developed to explore relationships among subject demographics and mobility metrics.

Results: Results showed minor limitations in the mild group while the more severe types showed more significant limitations in all mobility metrics analyzed. Height and weight were shown to be the most significant predictors of mobility. Relationships with mobility and bisphosphonates varied with OI type and type used (oral/IV).

Conclusion: These results are significant to understanding mobility limitations of specific types of OI and beneficial when developing rehabilitation protocols for this population. It is important for physicians, patients, and caregivers to gain insight into severity and classification of the disease and the influence of disease-related characteristics on prognosis for mobility.

Genetics in Medicine (2019) 21:2311-2318; https://doi.org/10.1038/s41436019-0491-4

Keywords: osteogenesis imperfecta; mobility; bone; rare disease; gait

\section{INTRODUCTION}

Osteogenesis imperfecta (OI) is a genetic connective tissue disorder characterized by increased bone fragility and recurrent fractures ${ }^{1}$ that has an estimated prevalence of $1: 10,000$ individuals. $^{2}$ OI is classified into various types depending on the disease severity and the genetic basis of the disorder. Sillence originally described four types (I-classic nondeforming, II-perinatally lethal, III-progressively deforming OI, IV-common variable OI). However, recent advances in understanding the molecular basis of OI have expanded the number of subtypes to 16 (refs. ${ }^{3,4}$ ). Heightened diagnostic awareness and improved treatments, particularly in severe forms, have increased the number of individuals living with OI. ${ }^{5}$

The severity of the disease influences the ability to walk. ${ }^{6}$ Subjects present with complications such as fracture, postfracture deconditioning, ligament laxity, upper and lower extremity deformity, and muscle weakness, which impair the ability to participate in activities. There is a relationship between bone mineral density and the functional outcome, rate of fracture, and rate of surgery in patients with osteogenesis imperfecta. ${ }^{7}$ Height deficit has also been shown to be related to severity of the condition. ${ }^{8}$ Little is known, however, regarding the ambulatory characteristics, strength,

\footnotetext{
${ }^{1}$ Orthopaedic Rehabilitation and Engineering Center, Marquette University, Milwaukee, WI, USA; ${ }^{2}$ Motion Analysis Laboratory, Shriners Hospitals for Children, Chicago, IL, USA; ${ }^{3}$ Baylor College of Medicine, Houston, TX, USA; ${ }^{4}$ Texas Children's Hospital, Houston, TX, USA; ${ }^{5}$ Department of Bone and Osteogenesis Imperfecta, Kennedy Krieger Institute, Baltimore, MD, USA; ${ }^{6}$ Department of Medicine at Uniformed Services University of the Health Sciences, Bethesda, MD, USA; ${ }^{7}$ University of Wisconsin School of Medicine and Public Health, Madison, WI, USA; ${ }^{8}$ Pediatrics and Molecular and Medical Genetics, Oregon Health \& Science University, Portland, OR, USA; ${ }^{9}$ Division of Medical Genetics, Alfred I du Pont Hospital for Children, Wilmington, DE, USA; ${ }^{10}$ Osteogenesis Imperfecta Foundation, Gaithersburg, MD, USA; ${ }^{11}$ College of Medicine, University of South Florida, Tampa, FL, USA; ${ }^{12}$ Departments of Medicine and Pathology, Division of Medical Genetics, University of Washington, Seattle, WA, USA; ${ }^{13}$ Shriner's Hospital for Children and McGill University, Montreal, QC, Canada; ${ }^{14}$ Children's Mercy Hospital, University of Missouri-Kansas City, Kansas City, MO, USA. Correspondence: Karen M. Kruger (karen. kruger@marquette.edu)
} 
or functional abilities associated with OI, especially in types other than type I.

The phenotypic severity of OI is the single most important clinical indicator of the ultimate ability to walk. ${ }^{6}$ Little is known, however, about the ambulatory characteristics, strength, or functional abilities in individuals with OI, especially in the more severe forms. ${ }^{1}$ A recent report showed children with type I OI to be as active as typically developing peers. ${ }^{9}$ Studies using the Pediatric Outcomes Data Collection Instrument (PODCI) in OI showed little difference from control group for basic mobility and function but lower scores than their peers in sports and physical function. ${ }^{10}$ Quantitative assessments have shown subtle measurable deficiencies of mobility and strength, mainly in type I cases. ${ }^{10,11}$ While it is known that individuals with the severe types of OI have significant limitations in mobility, the variability within these groups has precluded any conclusions about the effects of modern treatment such as bisphosphonate medication, surgery, and physical therapy on this parameter. ${ }^{12}$

There is no cure for OI; therefore, treatment strategies focus primarily on conservative and surgical intervention. Treatment for OI, particularly in severe cases, requires a multidisciplinary approach including corrective orthopedic interventions (i.e., rodding) and rehabilitation services. ${ }^{12}$ Bisphosphonate therapy through either oral or intravenous use is also often used in an attempt to increase bone mineral density and reduce fracture rate. The goals of treatment of OI are to maximize mobility and daily life competencies and decrease bone pain and bone fragility. Knowledge of the natural course of the disease is essential to interpret the results from intervention studies. ${ }^{13}$

How to prescribe treatment remains an important clinical question. Zeitlin et al. have stressed treatment for OI, particularly in severe cases, needs to be a multidisciplinary approach including bisphosphonate therapy, corrective orthopedic interventions, and physical therapy. ${ }^{12}$ The criteria for dividing individuals with OI into treatment groups has been subject to debate. Engelbert et al. suggested degree of intervention needed depends on severity of the clinical phenotype. ${ }^{13}$ In contrast, Sousa suggested the Sillence classification does not direct clinical patient care regarding treatments and interventions utilized and that treatment criteria should be established based on the number of fractures experienced per year. ${ }^{14}$ They argued that the Sillence classification is not uniformly predictive of which patients with OI will qualify for pamidronate therapy. Mobility outcomes and height have also been suggested as features to be taken into account for severity assessment and clinical classification of OI. ${ }^{15}$

It is well recognized that collaborative multicenter studies in rare diseases can lead to a better understanding of the natural history of disease, generate hypotheses for further research, and provide better therapeutic options for patients. ${ }^{16}$ Providing evidence-based answers to clinically relevant questions in OI is challenged by the rarity of the condition. To advance clinical research in OI, the Linked Clinical Research Centers
(LCRC), a network of five clinical centers in North America with significant experience in treating patients with OI, was established in 2009 (refs. ${ }^{17,18}$ ). The LCRC conducted the Longitudinal Study of Osteogenesis Imperfecta, an observational study wherein data were collected systematically across all participating sites. The purpose of this work was to characterize mobility in OI using standard clinical assessment tools. The specific goals of this paper are to report the range of various mobility metrics observed in each type of OI and determine if any patient characteristics could be used to predict mobility outcomes.

\section{MATERIALS AND METHODS}

The LCRC is comprised of five clinical sites across North America and a data collection and analysis center. ${ }^{18}$ Clinical sites included Baylor College of Medicine (Houston, TX), Shriners Hospital for Children (Chicago, IL), Kennedy Krieger Institute (Baltimore, MD) in collaboration with Nemours/Alfred I. DuPont Hospital for Children (Wilmington, DE), Oregon Health \& Science University (Portland, OR), and Shriners Hospital for Children (Montreal, Canada). The Data Collection and Analysis Center at the University of South Florida College of Medicine (Tampa, FL) served as the center for data collection and analyses. Approval of the research protocol was obtained from each participating site's institutional review board and informed consent was obtained from subjects or their legal guardians. Individuals with a clinical, molecular, or biochemical diagnosis of OI were enrolled. Genotypic information was used to appropriately classify patients when available. For those without a molecular or biochemical diagnosis, the site principal investigator (PI) and one of the two project PIs were required to be in agreement as to the clinical diagnosis and subtype of OI based upon specific criteria outlined by the study guidelines. ${ }^{18}$

Subjects were recruited through various sources including the OI Foundation, Children's Brittle Bone Foundation (CBBF), the OI registry, medical care providers, prenatal diagnostic centers, and local clinics during routine follow-up visits.

Mobility data was collected in accordance with detailed instructions in the Manual of Operations and the quality of data was assessed at the entry point using online case report forms. In addition, our data collection and analysis center identified missing or unclear data and generated data queries to the enrolling centers in addition to monitoring data delinquency to generate good-quality data. The following data were collected from all participants from a single visit: age, gender, ethnicity, height, weight, use of assistive device, and bisphosphonate use. The mobility metrics analyzed included age at first walk, Gillette Functional Assessment Questionnaire (FAQ) ${ }^{19}$ Functional Mobility Scale (FMS), ${ }^{20}$ and distance walked in the 6-minute walk test $(6 \mathrm{MWT}){ }^{21}$ The age at first walk was self-reported on a demographic form that asked participants to identify developmental milestones. The FAQ and FMS were administered as directed by the protocols outlined for each test metric. ${ }^{19,20}$ Finally, the 6 MWT was 
conducted in a hallway 100 meters long during which each subject used their typical mobility aids and wore comfortable clothing. Each participant was well rested before the test and had not exercised vigorously within 2 hours of beginning the test. All clinical sites had significant experience in evaluating these mobility metrics. In addition, study personnel were required to complete a study specific training and certification process prior to beginning work on the study. Data were analyzed from individuals who were over 3 years of age.

\section{Statistical analysis}

Multiregression analysis was used to determine the effect of predictor variables on mobility metrics. Mobility metrics analyzed were the FMS and 6MWT. Predictor variables included OI type, age at assessment, use of oral and intravenous bisphosphonate, height, weight, and gender. Using the preliminary results to identify predictor variables that correlated with FMS and 6MWT scores, linear mixed models were developed. Generalized mixed model linear regression accounted for subject effects. The correlation among our predictor variables was never higher than 0.25 in its absolute value. At such a large sample size, collinearity between predictors is not an issue. Due to the pattern of interactions with OI type observed during preliminary analysis, separate models were developed for types I, III, and IV. Models could not be developed for the other more rare types due to low subject numbers. These models were adjusted for within-individual correlations. Correlations between each mobility metric and predictor variable were examined by simple and multiple regression analyses. $P$ values $<0.01$ were considered statistically significant.

\section{RESULTS}

From 558 individuals enrolled in the study, 491 individuals were 3 years or older (average age: 19.0 years \pm 14.6 years, range 3.1 to 67.3 years). Subjects were identified with six OI types: 219 type I, 87 type III, 141 type IV, 17 type V, 10 type VI, 4 type VII, and 13 unclassified. Full subject demographic information including gender, race, age, height, and weight is included in Table 1. The age at first walk revealed that on average, children with type I started walking at age 1.3 years ( \pm 0.4 years), which is a delay of about 3 months compared with typically developing children. ${ }^{22}$ Individuals with other types of OI showed more significant delays. For the individuals who eventually walked, those with type III did so at age 3.8 years $( \pm 2.6$ years), type IV at 2.1 years $( \pm 1.7$ years), and type $\mathrm{V}$ at 1.5 years ( \pm 0.5 years).

The mobility metrics analyzed showed significant variability, especially in the more severe cases (Fig. 1) The FAQ walking ability scores revealed individuals with type I OI had the highest scores (average score 9.6, range 5-10, Fig. 1a). Individuals with type IV OI had lower scores (average 6.7, range 1-10), while individuals with type III OI scored 4.1 on average (range 1-10). Clinician-assigned FMS scale results demonstrated that most individuals with type I OI could walk completely independently on all surfaces while those with type III OI required a wheelchair or walker, especially at longer distances (Fig. 1b). Finally, individuals with OI of all types walked shorter distances in the 6MWT than healthy adults (Fig. 1c). On average, the distances walked by individuals with type I OI were $30 \%$ lower than typically developing individuals while those with type III who were able to complete the test had an average deficit of $62 \%$.

Results assessing for limitations to walking varied depending on OI type. Pain concerns ranked highest for type I (29\%), weakness highest for type III (43\%), and safety highest for type IV (40\%) (Fig. 2). The FAQ 22 questionnaire revealed that the majority of individuals with type I OI could perform tasks such as walking while carrying an object (99\%), walking up and down stairs using the railing (99\%), and taking a step backwards (98\%). In contrast, only $25-40 \%$ of individuals with type III OI could complete these tasks while $69-77 \%$ of individuals with type IV OI could. Ice/roller skating was ranked as the lowest task completion rate with $33 \%, 2 \%$, and $10 \%$ of individuals of OI types I, III, and IV, respectively, reporting being able to complete the task. A full summary of the 22-question exam is included in Supplement Table 1.

Requirement of assistive devices was variable by OI type. Of the individuals that responded, $4 \%, 40 \%$, and $24 \%$ of those with OI types I, III, and IV, respectively, required assistive devices. A walker was the most commonly used device, followed by crutches and a cane. Bisphosphonate use was reported by just over half of type I individuals while a large majority of individuals with the other types received either oral and intravenous bisphosphonate (type I: 55\%, type III: $90 \%$, type IV: $87 \%$, type V: $67 \%$, type VI: $100 \%$, type VII: $100 \%)$. Intravenous bisphosphonate use was more common than oral.

The results of the bivariate analyses showed that weight, height, use of intravenous bisphosphonate, and OI type were significant predictors of all mobility metrics assessed. Age and gender were not significant predictors for any of the mobility metrics analyzed. Multiregression analysis showed fewer correlations of statistical significance (Table 2). The results of this analysis can be used to predict these mobility outcomes for an individual subject. For example:

$$
\begin{aligned}
6 M W T(\text { meters })= & -500.91-8.05 \times \text { Weight }(\mathrm{kg}) \\
& +5.88 \times \text { Height }(\mathrm{cm})
\end{aligned}
$$

Many interactions were observed between the variables analyzed; therefore, the final regression analysis was performed by OI type. All groups except type I individuals who were not given bisphosphonate showed increased 6MWT distances with increasing height (Fig. 3a). This trend did not continue when analyzing correlation with weight (Fig. 3b). The type III group showed a strong correlation between increasing weight and increasing 6MWT for individuals on either IV or no bisphosphonates while the type I group showed only a slight trend of increased 6MWT distance with increased weight for those given intravenous bisphosphonate. 
Table 1 Demographic characteristics of patients at enrollment

\begin{tabular}{|c|c|c|c|c|c|c|c|c|}
\hline \multicolumn{9}{|c|}{$\underline{\mathrm{OI}^{\mathrm{a}} \text { type }}$} \\
\hline & & 1 & III & IV & V & VI & VII & Unclassified \\
\hline Enrollment & Male & 104 & 34 & 63 & 6 & 5 & 0 & 7 \\
\hline$(n)$ & Total & 219 & 87 & 141 & 17 & 10 & 4 & 13 \\
\hline \multirow[t]{2}{*}{ Race \% } & White & $93.6 \%$ & $81.4 \%$ & $85.7 \%$ & $81.3 \%$ & $70.0 \%$ & $50.0 \%$ & $76.9 \%$ \\
\hline & Black & $0.9 \%$ & $4.7 \%$ & $6.4 \%$ & $6.3 \%$ & $0.0 \%$ & $0.0 \%$ & $15.4 \%$ \\
\hline $\begin{array}{l}\text { Age } \\
\text { (years) }\end{array}$ & $\begin{array}{l}\text { Average } \\
\text { (range) }\end{array}$ & $\begin{array}{l}21.5 \\
(3.1-67.3)\end{array}$ & $\begin{array}{l}17.6 \\
(3.2-54.1)\end{array}$ & $17.3(3.1-62.7)$ & $\begin{array}{l}17.5 \\
(3.1-39.7)\end{array}$ & $13.9(3.6-31.5)$ & $\begin{array}{l}9.3 \\
(4.0-20.2)\end{array}$ & $\begin{array}{l}13.7 \\
(6.9-32.9)\end{array}$ \\
\hline $\begin{array}{l}\text { Height } \\
(\mathrm{cm})\end{array}$ & $\begin{array}{l}\text { Average } \\
\text { (range) }\end{array}$ & $\begin{array}{l}150.5 \\
(55.9-188)\end{array}$ & $\begin{array}{l}100.9 \\
(48.4-141)\end{array}$ & $\begin{array}{l}133.448 \\
(70.3-170.1)\end{array}$ & $\begin{array}{l}132 \\
(78.2-177.5)\end{array}$ & $\begin{array}{l}132.5 \\
(106.0-162.4)\end{array}$ & $\begin{array}{l}112.4 \\
(76.7-98)\end{array}$ & $\begin{array}{l}122.2 \\
(98-152.7)\end{array}$ \\
\hline $\begin{array}{l}\text { Weight } \\
(\mathrm{kg})\end{array}$ & $\begin{array}{l}\text { Average } \\
\text { (range) }\end{array}$ & $\begin{array}{l}53.9 \\
(12.5-168.0)\end{array}$ & $\begin{array}{l}29.5 \\
(5.9-98.0)\end{array}$ & $\begin{array}{l}46.3 \\
(10.8-111.4)\end{array}$ & $\begin{array}{l}53.8 \\
(12.5-160.1)\end{array}$ & $42.7(22.9-64.8)$ & $\begin{array}{l}38.3 \\
(13.0-85.5)\end{array}$ & $\begin{array}{l}34.7 \\
(17.6-54.8)\end{array}$ \\
\hline
\end{tabular}

${ }^{\mathrm{a}} \mathrm{Ol}$ osteogenesis imperfecta.

a

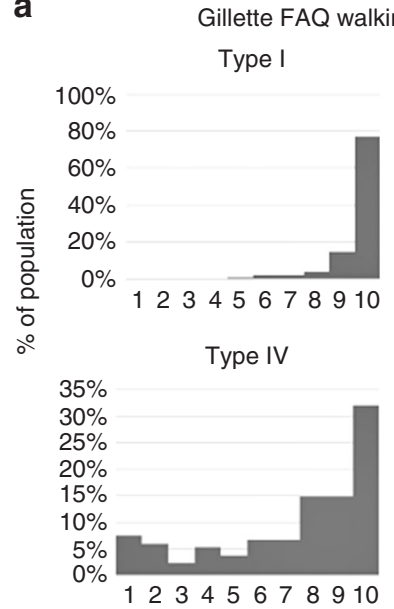

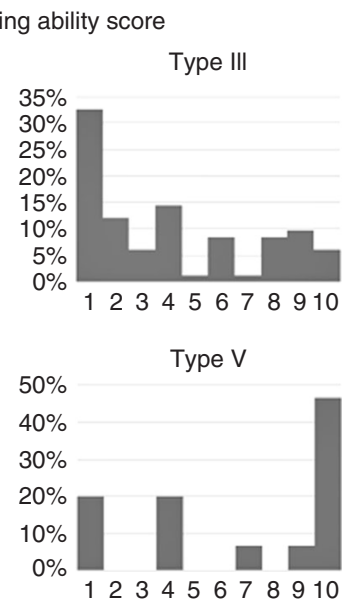

b
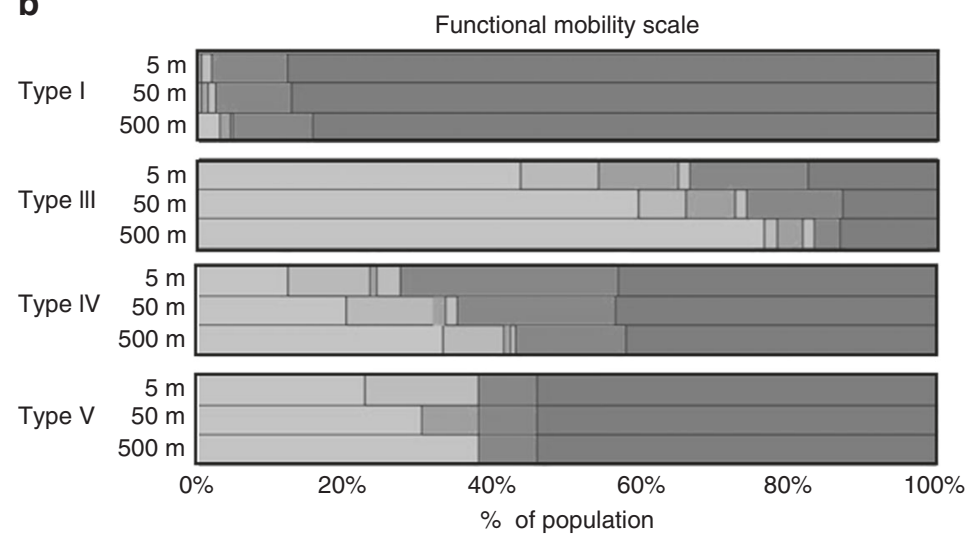

FMS score: $\square 1 \square 2 \square 3 \square 4 \square 5 \square 6$

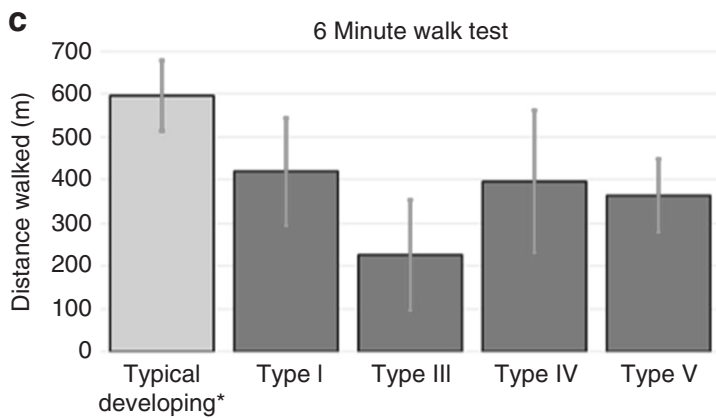

Fig. 1 Results of various mobility outcomes. a Gillette Functional Assessment Questionnaire (FAQ) Walking Ability Score. b Functional Mobility Scale (FMS). c Distance walked in 6-minute walk test $(\mathrm{m})$.

\section{DISCUSSION}

The prognosis for mobility of a child with OI is of clinical interest when setting goals for rehabilitation. Children and young adults with OI often experience a reoccurring cyclical pattern involving fracture, weakness, and deconditioning, which leads to functional limitations. ${ }^{11}$ A 2018 consensus report on physical rehabilitation in children and adolescents with osteogenesis imperfecta stressed that the overall treatment goal for children with OI is to maximize mobility, function, activities, and participation, and also noted that fear of fracture is the most limiting factor to reaching full 


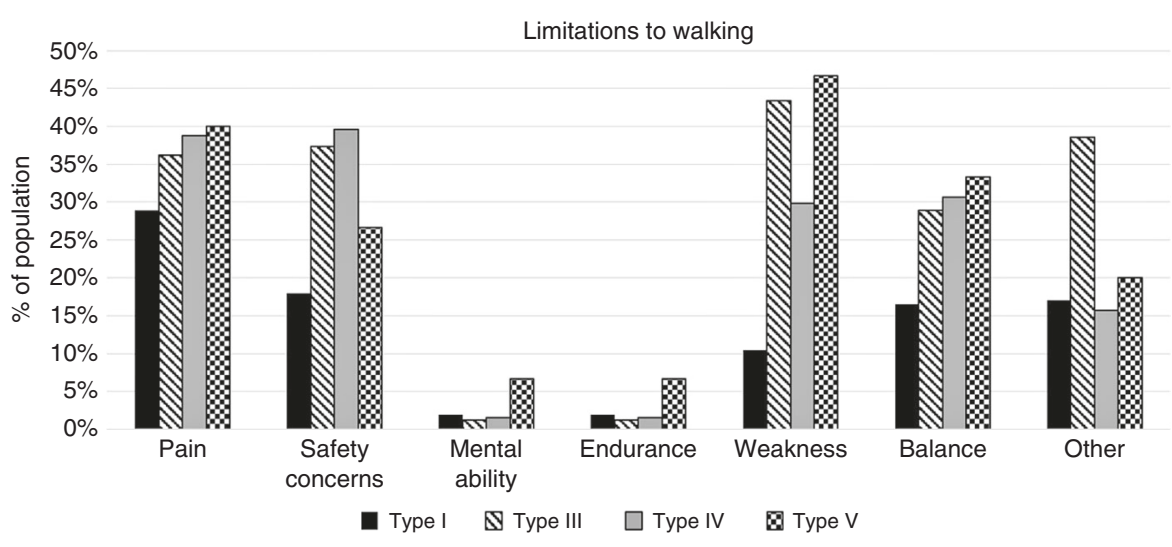

Fig. 2 Gillette FAQ limitations to walking.

Table 2 Results of regression analysis

\begin{tabular}{lllll} 
& 6MWT & $\begin{array}{l}\text { FMS: } \\
5 \mathrm{~m}\end{array}$ & $\begin{array}{l}\text { FMS: } \\
50 \mathrm{~m}\end{array}$ & $\begin{array}{l}\text { FMS: } \\
500 \mathrm{~m}\end{array}$ \\
\hline (Intercept) & -500.907 & -4.973 & -0.974 & 1.149 \\
Age & 3.367 & 0.009 & -0.002 & 0.003 \\
\hline Weight & $-8.053^{\mathrm{a}}$ & -0.019 & 0.009 & -0.005 \\
\hline Height & $5.881^{\mathrm{a}}$ & $0.074^{\mathrm{a}}$ & $0.047^{\mathrm{a}}$ & 0.044 \\
\hline $\begin{array}{l}\text { Years (IV } \\
\text { bisphosphonate) }\end{array}$ & -10.623 & 0.024 & 0.046 & 0.054 \\
\hline $\begin{array}{l}\text { Years (oral } \\
\text { bisphosphonate) }\end{array}$ & -5.917 & -0.048 & -0.06 & -0.068 \\
\hline Marginal R & & & & \\
\hline Conditional R & 0.267 & 0.315 & 0.377 & 0.432 \\
\hline
\end{tabular}

6MWT 6-minute walk test, FMS Functional Mobility Scale.

a Variable was a statistically significant predictor of mobility metric. Values represent intercept and slope for multivariable regression equations as reported in Equation 1. R package sjstats was used to calculate the marginal and conditional $\mathrm{R}^{2}$ values.

potential. ${ }^{23}$ Understanding disease-related characteristics specific to each type allows for more accurate patient comparisons and expectations. Maintaining the highest level of physical activity possible without injury is a primary goal when setting rehabilitation strategies. Successful rehabilitative intervention in mild to moderate OI seeks to maintain an appropriate loading environment to promote independence in the face of impairments from bone fragility.

Physical activity is important in maintaining strength and preventing other disorders including cardiovascular diseases and diabetes. ${ }^{24}$ Furthermore, youth with OI expressed disappointment in missing out on physical activities such as running due to tiring more easily than their more able-bodied peers. ${ }^{25}$ Therefore, all efforts should be made to maximize mobility in individuals with OI. Efforts have been made to study the impact of functional exercise on children with OI and have found that a standardized fitness program can improve aerobic performance and muscle strength. ${ }^{26}$ Several reports have also been published on the increased prevalence of obesity in patients with OI, with type III patients being the most severely affected, ${ }^{27-29}$ further demonstrating the importance of promoting physical activity within this population.

The results of the statistical analysis showed only relatively minor associations between the predictor variables and mobility outcome measures. As is shown in our results, height deficit is related to worse mobility outcomes, agreeing with literature where height has been related with severity of the condition. ${ }^{8,30}$ While body mass index (BMI) was not explicitly used as a predictor variable for this analysis, the interactions of height and weight were explored as part of the multivariate analysis and showed no associations for any of the mobility outcomes analyzed. These results indicate that the predictor variables commonly used to describe individuals with OI are not adequate to thoroughly describe mobility deficits for individuals with OI. Future work with this consortium and other groups who treat individuals with OI should use more detailed data including strength assessment and gait analysis to assess and set rehabilitation goals. There have been some reports on strength and gait characteristics that had small sample sizes and were limited to type I cases. ${ }^{10,11}$ Future work should include larger patient populations of all OI types to gain further understanding of functional limitations associated with various types of OI. This information will be vital to prescribing the best treatment to address these limitations. Normative data presented here such as $6 \mathrm{MWT}$ and other parameters can also be used as outcome measures in clinical trials in this population.

Benefits of bisphosphonates in mobility remain inconclusive. $^{31}$ Land et al. reported that cyclical pamidronate treatment improves mobility, ambulation level, and muscle force in children with moderate to severe $\mathrm{OI}^{32}$ while Seikaly reported improvements in well-being scores and self-care abilities but no change in mobility in patients treated with alendronate. ${ }^{33}$ Other reports found no changes in mobility or functional outcomes using oral ${ }^{34-36}$ or intravenous bisphosphonates. ${ }^{37}$ In agreement with these studies, our results showed no significant relationship between years on bisphosphonate treatment and mobility outcomes. However, it is 
a

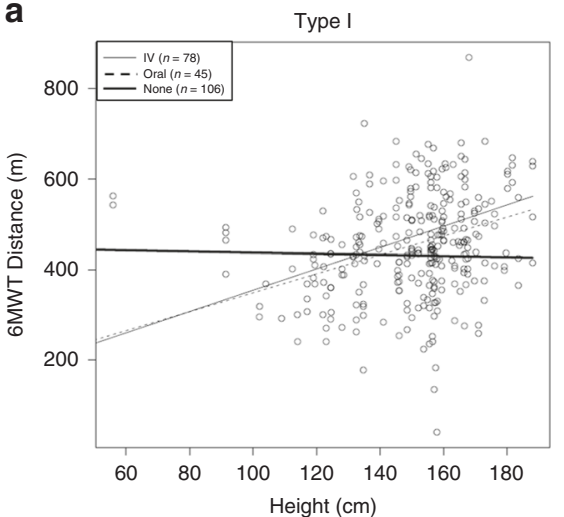

b

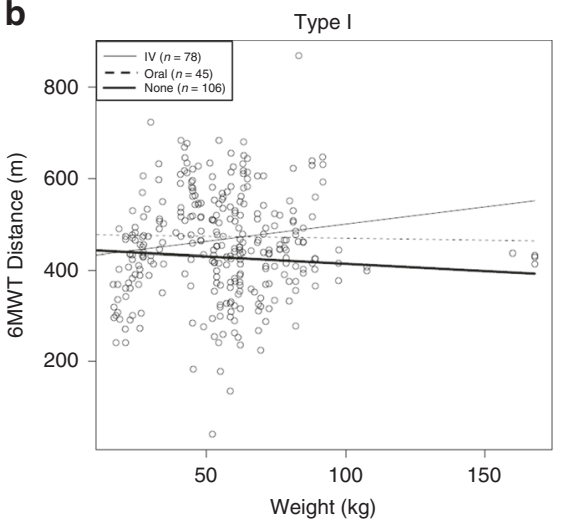

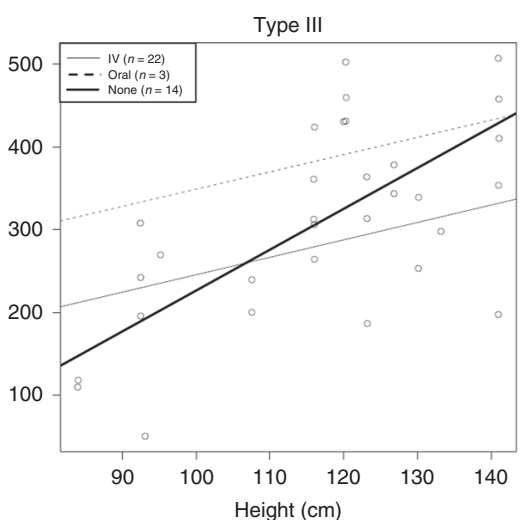
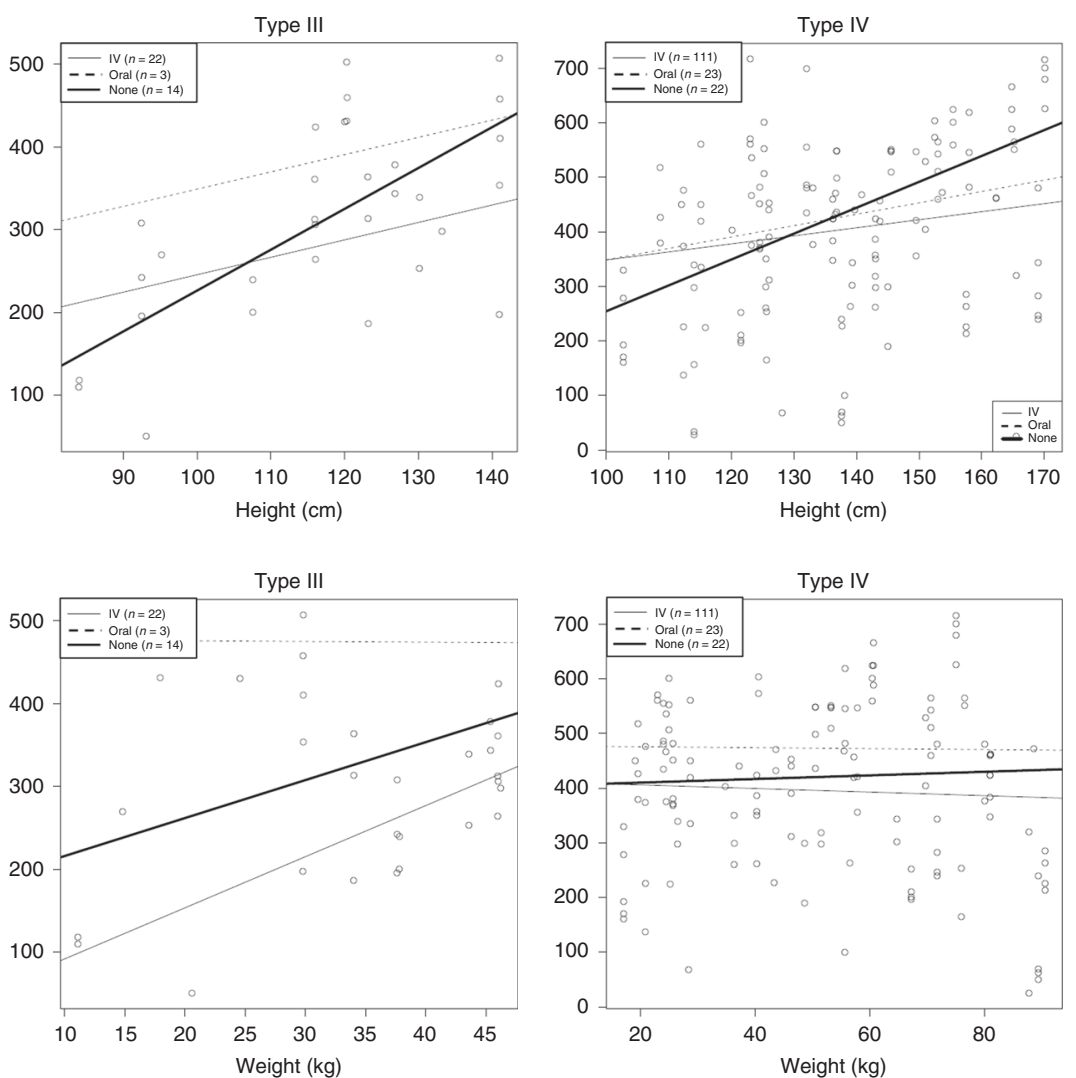

Fig. 3 Results of regression analysis by osteogenesis imperfecta (OI) type for predictor variables showing correlation. a Relationship between height and 6-minute walk test (6MWT) and (b) relationship between weight and 6MWT for subjects who were given oral, intravenous (IV), or no bisphosphonate treatment. The total number of subjects for each regression analysis is indicated on each graph.

important to note that the effect of the medication is affected by different factors such as age of starting, duration of the treatment, severity of the condition, and the association with other multidisciplinary approaches including physiotherapy and corrective surgery. ${ }^{38,39}$ The most important predictor of mobility remains phenotype.

This work is limited in that the FAQ and FMS are subjective in nature. Both the 10-point walking scale and 22-item skill set questionnaire have been validated as suitable for measuring locomotor skill ability in children. While they provide a better overall view of community functional ability, they are subjective to a degree and quantitative kinematics would be a useful tool to use in conjunction with these data.

Some individuals with more severe forms of OI scored higher than expected on several aspects of the FAQ. One possible explanation for this is that children with OI types III and IV sometimes use wheelchairs for sports activities and have different expectations than unaffected children. ${ }^{40}$ This makes comparison of patient reported outcome in these heterogeneous groups difficult.

The FMS, while still subjective, is a clinician-assigned score that could be reasonably expected to yield more consistent results than the FAQ, while 6MWT is an objective measure. Neither of these had a strong correlation to the patient characteristics analyzed. This suggests more detailed mobility data such as strength testing and gait analysis should be analyzed to gain insight into mobility limitations. This has been analyzed in small groups of individuals with type I OI. Strength testing revealed decreased heel-rise strength and ankle isometric plantar flexion strength. ${ }^{11}$ Results of a gait study showed the OI population demonstrated abnormal gait parameters including increased double support, delayed foot off, reduced ankle range of motion and plantar flexion during third rocker, along with greater ankle power absorption during terminal stance and reduced ankle power generation during push off. ${ }^{10}$ Together, these findings provide a comprehensive description of gait characteristics among a group of individuals with type I OI. Such data inform clinicians about specific gait deviations in this population, allowing clinicians to recommend more focused interventions; however, no such analysis has been completed on the more severe OI types.

In conclusion, this study reports cross-sectional data from the largest study of OI mobility conducted to date. Results are vital to understanding the mobility limitations of specific types of OI and beneficial when developing rehabilitation protocols for this population. It is important for physicians, patients, and caregivers to gain insight into severity and classification of the disease and the influence of diseaserelated characteristics on the prognosis for mobility. Future 
work can address how fracture history and surgical rodding impact these aspects of mobility.

\section{SUPPLEMENTARY INFORMATION}

The online version of this article (https://doi.org/10.1038/s41436019-0491-4) contains supplementary material, which is available to authorized users.

\section{ACKNOWLEDGEMENTS}

We thank Sergey Tarima and Alexis Visotcky for their statistical consultation and the members of the Brittle Bone Disease (BBD) Consortium (Jean Marc Retrouvey, Faculty of Dentistry, McGill University, Montreal; Paul Esposito, University of Nebraska Medical Center, Omaha; David Eyre, Department of Orthopedic and Sports Medicine, University of Washington, Seattle; Danielle Gomez, Shriners Hospital for Children, Tampa; Gerald Harris, Marquette University and Medical College of Wisconsin; Mahim Jain, Departments of Bone and Osteogenesis Imperfecta, Kennedy Krieger Institute, Baltimore; Deborah Krakow, Departments of Orthopedic Surgery and Obstetrics and Gynecology, David Geffen School of Medicine, University of California-Los Angeles; Eric Orwoll, Department of Medicine, Division of Endocrinology, Oregon Health \& Science University, Portland; Cathleen Raggio, Hospital for Special Surgery, New York; Laura Tosi, Bone Health Program, Children's National Health System, Washington, DC). Funding was provided by Children's Brittle Bone Foundation, OI Foundation, and National Institute on Disability, Independent Living, and Rehabilitation Research (NIDLRR) Grant 90AR5022-01.

\section{DISCLOSURE}

R.D.S. has equity interest in and has received consulting fees from Acer Therapeutics and Censa Pharmaceuticals. He has served as a consultant with compensation for Retrophin. He is principal investigator of an investigator-initiated observational research study funded by Alexion via a contract with Marshfield Clinic Health System. In the past five years he has received travel support from Pfizer and consulting fees from Raptor, Biomarin, Health Advances, Precision for Value, and Best Doctors. He is an employee of PreventionGenetics, and served as an expert reviewer for legal cases related to medical malpractice claims. He has one patent awarded but not licensed (no revenue) and a second patent pending both in the areas of newborn screening for sterol and bile acid disorders. F.R. reports personal fees from Alexion Inc. outside the submitted work. The other authors declare no conflicts of interest.

Publisher's note: Springer Nature remains neutral with regard to jurisdictional claims in published maps and institutional affiliations.

\section{REFERENCES}

1. Engelbert RH, Pruiis HE, Beemer FA, Helders PJ. Osteogenesis imperfecta in childhood: treatment strategies. Arch Phys Med Rehabil. 1998;79:1590-1594.

2. Byers S. Osteogenesis imperfecta. Annu Rev Med. 1992;43:269-282.
3. Forlino A, Marini JC. Osteogenesis imperfecta. Lancet. 2016;387:1657-1671.

4. Bacon S, Crowley R. Developments in rare bone diseases and mineral disorders. Ther Adv Chronic Dis. 2018;9:51-60.

5. Singer RB, Ogston SA, Paterson CR. Mortality in various types of osteogenesis imperfecta. J Insur Med. 2001;33:216-220.

6. Engelbert RH, Uiterwaal CS, Gulmans VA, Pruijs H, Helders PJ. Osteogenesis imperfecta in childhood: prognosis for walking. J Pediatr. 2000;137:397-402.

7. Huang RP, Ambrose CG, Sullivan E, Haynes RJ. Functional significance of bone density measurements in children with osteogenesis imperfecta. J Bone Joint Surg Am. 2006;88:13241330.

8. Ben Amor IM, Glorieux FH, Rauch F. Genotype-phenotype correlations in autosomal dominant osteogenesis imperfecta. J Osteoporos. 2011;2011:540178

9. Pouliot-Laforte A, Veilleux LN, Rauch F, Lemay M. Physical activity in youth with osteogenesis imperfecta type I. J Musculoskelet Neuronal Interact. 2015;15:171-176.

10. Graf A, Hassani S, Krzak J, et al. Gait characteristics and functional assessment of children with type I osteogenesis imperfecta. J Orthop Res. 2009;27:1182-1190.

11. Caudill A, Flanagan A, Hassani $S$, et al. Ankle strength and functional limitations in children and adolescents with type 1 osteogenesis imperfecta. Pediatr Phys Ther. 2010;22:288-295.

12. Zeitlin L, Fassier F, Glorieux FH. Modern approach to children with osteogenesis imperfecta. J Pediatr Orthop B. 2003;12:77-87.

13. Engelbert RH, Uiterwaal CS, Gerver WJ, van der Net JJ, Pruijs HE, Helders PJ. Osteogenesis imperfecta in childhood: impairment and disability. A prospective study with 4-year follow-up. Arch Phys Med Rehabil. 2004;85:772-778.

14. Sousa T, Bompadre V, White KK. Musculoskeletal functional outcomes in children with osteogenesis imperfecta: associations with disease severity and pamidronate therapy. J Pediatr Orthop. 2014;34:118-122.

15. Van Dijk FS, Sillence DO. Osteogenesis imperfecta: clinical diagnosis, nomenclature and severity assessment. Am J Med Genet A. 2014;164a:1470-1481.

16. Richesson RL, Sutphen R, Shereff D, Krischer JP. The Rare Diseases Clinical Research Network Contact Registry update: features and functionality. Contemp Clin Trials. 2012;33:647-656.

17. Bellur S, Jain M, Cuthbertson D, et al. Cesarean delivery is not associated with decreased at-birth fracture rates in osteogenesis imperfecta. Genet Med. 2016;18:570-576.

18. Patel RM, Nagamani SC, Cuthbertson D, et al. A cross-sectional multicenter study of osteogenesis imperfecta in North Americaresults from the linked clinical research centers. Clin Genet. 2015;87:133-140.

19. Novacheck TF, Stout JL, Tervo R. Reliability and validity of the Gillette Functional Assessment Questionnaire as an outcome measure in children with walking disabilities. J Pediatr Orthop. 2000;20:75-81.

20. Graham HK, Harvey A, Rodda J, Nattrass GR, Pirpiris M. The Functional Mobility Scale (FMS). J Pediatr Orthop. 2004;24:514-520.

21. Geiger R, Strasak A, Treml B, et al. Six-minute walk test in children and adolescents. J Pediatr. 2007;150:395-399.

22. Capute AJ, Shapiro BK, Palmer FB, Ross A, Wachtel RC. Normal gross motor development: the influences of race, sex and socio-economic status. Dev Med Child Neurol. 1985;27:635-643.

23. Mueller B, Engelbert R, Baratta-Ziska F, et al. Consensus statement on physical rehabilitation in children and adolescents with osteogenesis imperfecta. Orphanet J Rare Dis. 2018;13:158.

24. Haskell WL, Lee IM, Pate RR, et al. Physical activity and public health: updated recommendation for adults from the American College of Sports Medicine and the American Heart Association. Med Sci Sports Exerc. 2007;39:1423-1434.

25. Hill CL, Baird WO, Walters SJ. Quality of life in children and adolescents with osteogenesis imperfecta: a qualitative interview based study. Health Qual Life Outcomes. 2014;12:54.

26. Van Brussel M, Takken T, Uiterwaal CS, et al. Physical training in children with osteogenesis imperfecta. J Pediatr. 2008;152:111-116.

27. Germain-Lee EL, Brennen FS, Stern D, et al. Cross-sectional and longitudinal growth patterns in osteogenesis imperfecta: implications for clinical care. Pediatr Res. 2016;79:489-495.

28. Chagas CE, Roque JP, Santarosa Emo Peters B, Lazaretti-Castro M, Martini LA. Do patients with osteogenesis imperfecta need individualized nutritional support? Nutrition. 2012;28:138-142. 
29. Zambrano MB, Brizola ES, Refosco L, Giugliani R, Felix TM. Anthropometry, nutritional status, and dietary intake in pediatric patients with osteogenesis imperfecta. J Am Coll Nutr. 2014;33:18-25.

30. Rauch F, Lalic L, Roughley P, Glorieux FH. Genotype-phenotype correlations in nonlethal osteogenesis imperfecta caused by mutations in the helical domain of collagen type I. Eur J Hum Genet. 2010;18:642-647.

31. Dwan K, Phillipi CA, Steiner RD, Basel D Bisphosphonate therapy for osteogenesis imperfecta. The Cochrane database of systematic reviews. 2014:Cd005088.

32. Land C, Rauch F, Montpetit K, Ruck-Gibis J, Glorieux FH. Effect of intravenous pamidronate therapy on functional abilities and level of ambulation in children with osteogenesis imperfecta. J Pediatr. 2006;148:456-460.

33. Seikaly MG, Kopanati S, Salhab N, et al. Impact of alendronate on quality of life in children with osteogenesis imperfecta. J Pediatr Orthop. 2005;25:786-791.

34. Sakkers $R$, Kok $D$, Engelbert $R$, et al. Skeletal effects and functional outcome with olpadronate in children with osteogenesis imperfecta: a 2year randomised placebo-controlled study. Lancet. 2004;363:1427-1431.
35. Ward LM, Rauch F, Whyte MP, et al. Alendronate for the treatment of pediatric osteogenesis imperfecta: a randomized placebo-controlled study. J Clin Endocrinol Metab. 2011;96:355-364.

36. Bishop N, Harrison R, Ahmed F, et al. A randomized, controlled doseranging study of risedronate in children with moderate and severe osteogenesis imperfecta. J Bone Mineral Res. 2010;25:32-40.

37. Letocha AD, Cintas HL, Troendle JF, et al. Controlled trial of pamidronate in children with types III and IV osteogenesis imperfecta confirms vertebral gains but not short-term functional improvement. J Bone Mineral Res. 2005;20:977-986.

38. Astrom E, Soderhall S. Beneficial effect of long term intravenous bisphosphonate treatment of osteogenesis imperfecta. Arch Dis Child. 2002;86:356-364.

39. Montpetit K, Palomo T, Glorieux FH, Fassier F, Rauch F. Multidisciplinary treatment of severe osteogenesis imperfecta: functional outcomes at skeletal maturity. Arch Phys Med Rehabil. 2015;96:1834-1839.

40. Engelbert RH, Gulmans VA, Uiterwaal CS, Helders PJ. Osteogenesis imperfecta in childhood: perceived competence in relation to impairment and disability. Arch Phys Med Rehabil. 2001;82:943-948. 